\title{
Correction to: Influence of the Strain History on TWIP Steel Deformation Mechanisms in the Deep-Drawing Process
}

\author{
R. LAPOVOK, I. TIMOKHINA, K. MESTER, M. WEISS, and A. SHEKHTER
}

https://doi.org/10.1007/s11661-018-4879-6

(c) The Minerals, Metals \& Materials Society and ASM International 2018

\section{Correction to:}

Metallurgical and Materials Transactions A,

Volume 49A, June 2018, pp. 2069-2083

https://doi.org/10.1007/s11661-018-4586-3

IN the original article K. Mester's first name is incorrect. It is correct as reflected here.

R. LAPOVOK, I. TIMOKHINA, K. MESTER, and M. WEISS are with the Institute for Frontier Materials, Deakin University, Waurn Ponds, VIC 3216, Australia. Contact e-mail: r.lapovok@deakin.edu.au A. SHEKHTER is with the Aerospace Division, Defence Science and Technology, Fisherman's Bend, VIC 3207, Australia.

The original article can be found online at https://doi.org/10.1007/ s11661-018-4586-3.

Article published online August 20, 2018 